\title{
Research on the application of experience-based materials in product innovation design.
}

\author{
XitongHu $^{1}$, WeiguoZhang ${ }^{2}$, JianyaoShu ${ }^{3}$, FangWang ${ }^{4}$, QimengNie ${ }^{5}$ and YunMei ${ }^{*}$ \\ ${ }^{1}$ Industrial design, University of Science and Technology Liaoning, Anshan City, Liaoning Province, 114051, \\ China
}

\begin{abstract}
In order to explore the design characteristics and application of materials, the role of materials in product innovation design needs to be given full play. From the perspective of material characteristics, this paper studies the user experience and innovation of the design and application of paper characteristics, ceramics and other materials, and summarizes the application mode of material experience in product innovation. To enrich users' experience, it is necessary to break through the barrier of materials suitably, bring experience to users, and meet users' dual demands for product functions and emotions.
\end{abstract}

\section{$1 \quad$ Introduction}

In the current product design, the material used in the product is the material basis of the product and the embodiment of the overall social progress. A good design product must be the selection of appropriate materials, and materials for a certain amount of processing and manufacturing[1]. With the continuous development of modern science and technology, the innovation of material technology also promotes the innovative design of products. It can be said that the innovation of material technology and product innovation are complementary to each other. However, the application of materials in current product design is still too conservative, which restricts the use and innovation of different materials in products. Therefore, it is necessary to conduct innovative research on the emotional experience of different materials, and the application of innovative materials will bring different emotional experiences to users.

\section{Relationship between material experience and product innovation design}

\subsection{Materials are the basis of innovative product design}

"Materials are the basis of design, and the performance of materials determines the possibility of design." This sentence is from Philippe Starck, a famous French designer, this sentence affirms the importance of materials in product design and also applies to product innovation design. Survey results in the early 21 st century indicate that a growing number of authorities and researchers believe that new product design trends in the 21 st century and beyond are due to the innovative application of materials[2]. Therefore, it is not difficult to infer that the innovation of materials and their innovative application in products will be a development trend of future design. Material is one of the important elements in product innovation design, and the application, experience and emotion of material in product design play a crucial role in innovative design.

\subsection{Product innovation design is the carrier of material experience}

In recent years, user experience has been gradually attached importance to by designers and the public, and user experience has also been continuously researched and innovated. Donald Arthur Norman divides the emotional experience into three parts: the instinctive level, the behavioral level and the reflective level[3], and he then discusses the impact of user experience on design.

Based on the innovative design of the product and the application of different materials, the material experience changes accordingly. The continuous development of material experience is mainly attributed to the fact that product innovation design is the carrier of material experience, which promotes the development of material experience. The relationship between material experience and product innovation design is complementary, product innovation design is the material carrier of material experience, and material experience is an important part of product innovation design, it plays a perfect role in product innovation design and makes product innovation design method more comprehensive. Product innovation

*Corresponding author's e-mail: Inasmy@126.com 
design is not only the form and function innovation, but also needs to consider the application of materials and the different emotional experiences brought by different materials. Integrating the texture and semantics of materials into product design will also bring unique artistic beauty and lead users to yearn for aesthetics.

\section{Combined application analysis of material experience and product innovation design}

From the Bauhaus period in Germany, "Good design is innovative, meticulous, environmentally friendly and so on." The innovative design advocated by Bauhaus is the proper handling and application of material texture and characteristic elements to develop 'good design'. With the development of science and technology, people are increasingly pursuing customized and differentiated products, and the word 'experience' has entered the public view. Designers, users are in the pursuit of 'experience', user experience began to be pursued by businesses. Judging whether a product is a good product from the material point of view can be judged from its market point of view. Some products don't work as well in the market, partly because users may not get a good experience. The shape and function of a product are always important, but the user experience has a greater impact on the attractiveness of the product, and thus the market acceptance of the product. The combination of material application and user experience will be one of the directions of product innovation design in the future.

The famous Japanese architect Shigeru Ban was the designer of the Japan pavilion in the Hanover World EXPO in 2000, as shown in Figure 1. This time, the construction materials of the Japan pavilion are all made of recycled paper products. The outer layer of the paper products is protected by the craft of recycled paper, which extends the service life of the products and can be recycled after use. Mr. Ban, who won The Pritzker
Architecture Prize in 2014, has broken with conventional wisdom about building materials for disaster relief by applying his paper-tube architecture to buildings. This kind of paper-tube building is low-cost, environmentally friendly and recyclable. Combining the design concept of green sustainable development with innovative product design, Shigeru Ban has brought users a unique environmental and green experience. Recycled paper can be accepted by users, because recycled paper materials in the design have its own unique, this unique lies in that it can bring users different experience[4], and users also pursue novelty and diversity. The design point of product innovation design lies in users' recognition and experience. Good user experience indicates the value element of product innovation design. Rice hull material also has the characteristics of low cost, easy to shape, and green environmental protection. It can also carry out innovative design of rice hull material products, and apply rice hull material in disaster relief buildings to provide users with green user experience.

As shown in Figure 2, HUAWEI Watch GT series adopt the combination of metal, ceramic and plastic, and applies fine ceramic materials to the bezels of smart wearable watch products. The simple sense of different metal materials, the applications of ceramic to smart dressed in electronic products, use of ceramic materials unique touch and texture, enrich the visual effect of the product, the fine ceramic material with its excellent physical and chemical functions gives the electronic products, rich experience, users feel the creativity, technological. At present, fine ceramic materials are mainly used in electronic communication, chemical industry, biological medicine, metallurgy, machinery and other fields. The closest distance between fine ceramic materials and users is also the application of fine ceramic materials in biological teeth. HUAWEI has applied fine ceramic materials in smart wearable products, breaking the constraint of material application and initiating the application of fine ceramic materials in innovative design.
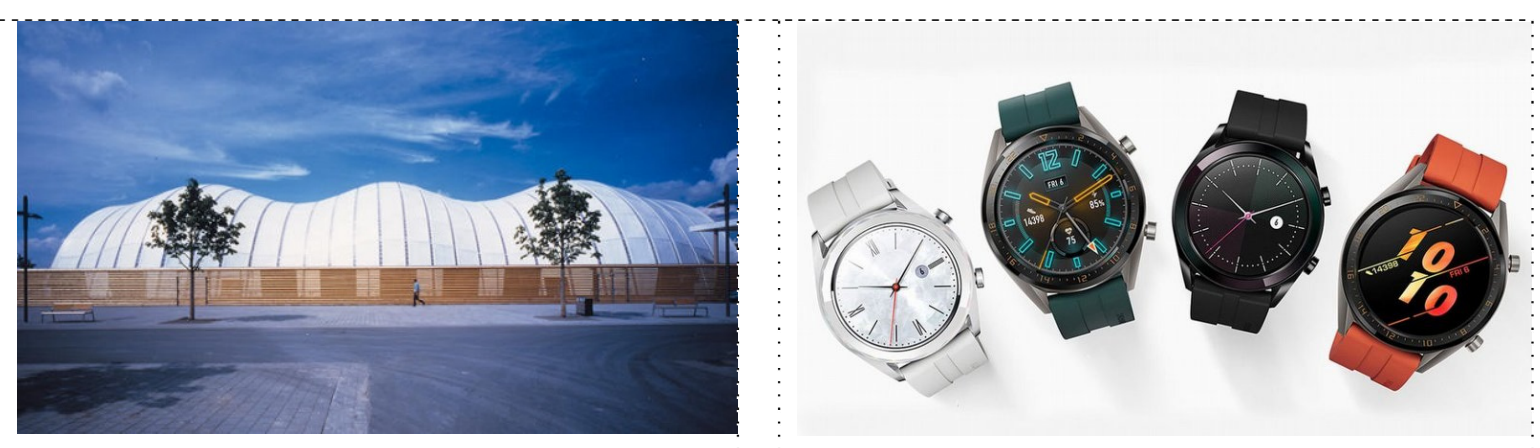

Figure 1. Japan Pavilion, Hannover Expo 2000

\section{$4 \quad$ Innovative experience of materials in product design}

Among the materials, including glass, ceramics, wood, bamboo and other metallic materials, these materials have their own material characteristics and different

\section{Figure 2. HUAWEI Watch GT series.}

emotional experiences. Any kind of material has its own unique texture and smell, which will provide users with emotional experience, such as the cold metal, difficult to access; comfortable woodiness, skin-friendly, elegant atmosphere of porcelain and so on. The innovative application of materials in product design can combine the innovative application of materials with user experience by breaking conventions and subverting the 
traditional use of materials. The beauty of material has always been pursued by everyone, the beauty of material is expressed through its texture, smell and vision. With the development of industrial technology, more and more new materials appear. The unique texture of new materials, such as the characteristics of fine ceramic materials, is an important element that distinguishes them from ordinary ceramic materials. At the same time, the modern sense and advanced nature brought by fine ceramic materials also bring modern and innovative experience to users. In the field of modern product design dominated by traditional materials such as plastic and metal, the application of traditional materials can be changed if traditional materials want to express their different characteristic elements.

Zhang F[5], put forward the application innovation of ceramic material art in modern soft decoration, which changed the selection of traditional household materials, integrated ceramic aesthetics into the life art of soft decoration, reflected the artistic conception and artistic atmosphere of ceramic art, and endowed users with artistic experience.

For product innovation design, the application of materials has a certain exploratory and guiding, and materials should not be bound by the characteristics of materials themselves. The material application of product innovation design can refer to three emotional experience parts, namely the instinct level, the behavior level and the reflection level. The product design can be integrated through the user experience at three levels to make the product reach a new height. The innovative design of materials application based on experience can be innovated from several aspects:

(1) Innovative design based on emotional spirit of material texture.

(2) New material application is combined with product innovation design.

(3) Breaking the conventional material application innovation, subvert the traditional application of materials.

(4) Similar material replacement product innovation design.

The appearance of a new material tends to promote the common development of other fields. There is a chair based on the shape of human red blood cells. This is due to the development of microscopy and material forming technology[6]. It indicates that the product innovation design not only promotes the design field, but also promotes the manufacturing industry and the material industry. Many industries, though seemingly separate, are actually interconnected.

\section{$5 \quad$ Conclusion}

In the contemporary consumption mode, the focus of consumers in purchasing products is not only the function, shape, technology and other aspects of the product, but also the experience the product provides to users and the emotional resonance it can generate with users. From the perspective of Maslow's hierarchy of needs, user needs are no longer physiological needs and security needs at the bottom of the pyramid, but higher levels of respect needs and self-needs. The innovative design of products should focus on 'respect needs' and 'self-needs' to provide users with products with reflective level and experience value. The same product shape and function can be combined with different materials for innovative product design, which will enhance the competitiveness of the product. By providing users with good product experience, the perfect combination of material experience and product innovation design can bring users deeper emotional experience, express the emotional power of materials, endow product design with new humanistic feelings, and meet the artistic aesthetic pursuit of social progress and development.

\section{References}

1. $\mathrm{Wu}, \mathrm{Q}$. (2011) On the selection of materials for product art design innovation. J. Packaging Engineering, 32(12): 123-126.

2. Charlotte. Peter, F. (2001) Designing the 21st Century. Taschen, Germany.

3. Donald, A, N. (2015) Design Psychology 3: Emotional Design. Citic Press, Beijing.

4. Wang, B. (2013) Research on innovative design of recycled paper based on experience. Beijing Forestry University Press, Beijing.

5. Zhang, F. (2016) Innovative thinking on the application of ceramic art in modern soft decoration. J. Furniture and Interior Decoration, (02): 86-87.

6. Wang, Y. (2020) Research on design innovation strategies and methods of CMF. J. Science and Technology Innovation and Application, (01): 9899. 